\title{
Endometrial stromal beta-catenin is required for steroid-dependent mesenchymal-epithelial cross talk and decidualization
}

\author{
Ling Zhang ${ }^{1+}$, Amanda L Patterson ${ }^{2}$, Lihua Zhang ${ }^{1}$, Jose M Teixeira ${ }^{1}$ and James K Pru²*
}

\begin{abstract}
Background: Beta-catenin is part of a protein complex associated with adherens junctions. When allowed to accumulate to sufficient levels in its dephosphorylated form, beta-catenin serves as a transcriptional co-activator associated with a number of signaling pathways, including steroid hormone signaling pathways.

Methods: To investigate the role of beta-catenin in progesterone $\left(\mathrm{P}_{4}\right)$ signaling and female reproductive physiology, conditional ablation of Ctnnb1 from the endometrial mesenchymal (i.e. stromal and myometrial), but not epithelial, compartment was accomplished using the Amhr2-Cre mice. Experiments were conducted to assess the ability of mutant female mice to undergo pregnancy and pseudopregnancy by or through oil-induced decidualization. The ability of uteri from mutant female mice to respond to estrogen $\left(E_{2}\right)$ and $P_{4}$ was also determined.

Results: Conditional deletion of Ctnnb1 from the mesenchymal compartment of the uterus resulted in infertility stemming, in part, from complete failure of the uterus to decidualize. $E_{2}$-stimulated epithelial cell mitosis and edematization were not altered in mutant uteri indicating that the mesenchyme is capable of responding to $\mathrm{E}_{2}$. However, exposure of ovariectomized mutant female mice to a combined $E_{2}$ and $P_{4}$ hormone regimen consistent with early pregnancy revealed that mesenchymal beta-catenin is essential for indirectly opposing $E_{2}$-induced epithelial proliferation by $\mathrm{P}_{4}$ and in some mice resulted in development of endometrial metaplasia. Lastly, betacatenin is also required for the induced expression of genes that are known to play a fundamental role in decidualization such as Ihh, Ptch1, Gli1 and Muc1

Conclusions: Three salient points derive from these studies. First, the findings demonstrate a mechanistic linkage between the $\mathrm{P}_{4}$ and beta-catenin signaling pathways. Second, they highlight an under appreciated role for the mesenchymal compartment in indirectly mediating $\mathrm{P}_{4}$ signaling to the epithelium, a process that intimately involves mesenchymal beta-catenin. Third, the technical feasibility of deleting genes in the mesenchymal compartment of the uterus in an effort to understand decidualization and post-natal interactions with the overlying epithelium has been demonstrated. It is concluded that beta-catenin plays an integral role in selective $\mathrm{P}_{4}$-directed epithelial-mesenchymal communication in both the estrous cycling and gravid uterus.
\end{abstract}

Keywords: Beta-catenin, Decidualization, Endometrium, Implantation, Pregnancy, Progesterone, Uterus

\footnotetext{
* Correspondence: jpru@wsu.edu

${ }^{\dagger}$ Equal contributors

2Department of Animal Sciences, Center for Reproductive Biology,

Washington State University, Pullman, WA 99164, USA

Full list of author information is available at the end of the article
} 


\section{Background}

The stromal/mesenchymal compartment of the endometrium performs a variety of tasks important for uterine physiology, including relaying specific aspects of steroid hormone signaling to the overlying epithelium. An example of such mesenchymal-to-epithelial signaling occurs in response to estradiol $\left(\mathrm{E}_{2}\right)$ binding to and activating estrogen receptor (ESR1), inducing the expression of stromal-derived growth factors that stimulate epithelial cell cycle progression, hypertrophy, and initiating secretory functions (reviewed in [1]). In invasively implanting species, the stroma also undergoes decidualization during early pregnancy following embryo apposition and attachment to the uterine luminal epithelium, a process inherently regulated by progesterone $\left(\mathrm{P}_{4}\right)$ following $\mathrm{E}_{2}$ priming. Here, stromal cells terminally differentiate and contribute to pregnancy by performing placenta-like functions until such time that the embryo develops its own nutrient and gas exchange apparatus, the placenta [2]. Stromal decidualization is regulated, in part, by cues derived from the epithelium such as Indian hedgehog.

It is thought that ESR1 mediates $\mathrm{E}_{2}$-initiated signaling in the uterus. However, it is generally understood that $\mathrm{E}_{2^{-}}$ initiated transcriptional and physiological changes occur in two phases [3]. The first occurs within 2-6 hours, and the second takes place between 24-72 hours. Although many $\mathrm{E}_{2}$-initiated transcriptional events require binding of ESR1 to estrogen response elements (ERE), many other genes are regulated in an ER-dependent, but ERE-independent fashion [4]. This suggests that ESR1 interacts with other transcriptional modulators that in turn interact with DNA to regulate gene expression at promoter sites distinct from EREs. Within the uterine epithelium, one such ESR1 interacting molecule is the transcriptional co-activator $\beta$-catenin $[5,6]$. The late transcriptional response to $E_{2}$ is thought to be mediated, in part, by the ESR1: $\beta$-catenin interaction. Equally complex signaling mechanisms likely coordinate $\mathrm{P}_{4}$ responses, but such pathways are less clearly understood.

$\beta$-catenin is best known for its central role in the canonical wingless-type MMTV integration site family member (Wnt) signaling pathways and $\beta$-catenin is essential for development, transcription, cell adhesion and tumorigenesis [7]. In the absence of Wnt signaling, $\beta$-catenin is found in the cytoplasm either as a component that binds cadherins to $\alpha$-catenin and the cytoskeleton at adherens junctions or in a complex with adenomatous polyposis coli (APC), axin, and glycogen synthase kinase $3 \beta$ (GSK-3 $\beta$ ), wherein it is phosphorylated and subject to ubiquitination and proteasomal degradation. Activation of frizzled receptors by Wnt ligands disrupts the APC complex and inhibits GSK-3 $\beta$ activity causing an accumulation of unphosphorylated (i.e., activated) $\beta$-catenin, which promotes its nuclear localization and subsequent regulation of target gene expression [8]. $\beta$-catenin is therefore uniquely situated at a bottleneck in the Wnt signaling pathway.

Much of the focus of steroid hormone signaling studies in the uterus has been directed at the epithelial compartment. In the present study, the function of $\beta$-catenin in the stromal compartment was investigated in the contexts of steroid hormone action and stromal cell decidualization. Our findings reveal that conditional inactivation of $\beta$-catenin in endometrial stroma results in disrupted progesterone signaling and complete loss of stromal cell decidua-lization, indicating that steroiddependent and $\beta$-catenin signaling pathways intersect to regulate postnatal uterine functions.

\section{Methods}

\section{Animals}

Animal protocols were approved by either the Massachusetts General Hospital or the Washington State University Institutional Care and Use Committee. For histology, mature (6-8 weeks old) ICR female mice were placed with intact ICR males of proven breeding capacity or with vasectomized ICR males. Female mice were considered day of pregnancy (DOP) or day of pseudopregnancy (DOPP) 0.5 upon observation of a vaginal seminal plug. Whole implantation sites (pregnancy) or mechanically decidualized uterine tissue (pseudopregnancy) were collected on days 4.5, 6.5 and 7.5 and prepared for RNA isolation or paraffin sectioning as described below. Decidualization was induced in pseudopregnant female mice by infusing $10 \mu \mathrm{l}$ of sesame oil into the uterine lumen on DOPP 4.

The utility of the anti-Müllerian hormone type II receptor $(A m h r 2)$ promoter to drive Cre recombinase expression in mice during uterine decidualization was first established by crossing $A m h r 2^{C r e}$ transgenic mice $\left(A m h r 2^{t m 3(c r e) B h r /+}\right)$, kindly provided by Dr. Richard Behringer or purchased from the Mutant Mouse Regional Resource Center, with Rosa-EYFP reporter mice containing a yellow fluorescent protein gene downstream of a loxp-flanked stop sequence (Gt(ROSA) $\left.26 \operatorname{Sor}^{\operatorname{tm} 1(E Y F P) C o s}\right)$ [9]. To study $\beta$-catenin function in endometrial stromal tissue $A m h r 2^{C r e}$ mice were mated with mice harboring a Ctnnb1 gene with exons 2-6 flanked by $\operatorname{loxP}$ sites (Ctnnb1 $1^{\text {tm2Kem/KnwJ }}$; The Jackson Laboratories, Bar Harbor, ME; [10]). Double transgenic Amhr2 $2^{\mathrm{Cre} /+}$;Ctnnb1 $1^{\text {flox/+ }}$ offspring derived from this first mating were then crossed to generate conditional mutant $\left(A m h r 2^{\mathrm{Cre} /{ }^{+}} ; \mathrm{Ctnnb} 1^{d / d}\right)$ and control $\left(A m h r 2^{\mathrm{Cre} /+}\right.$; $C t n n b 1^{d /+}$ or $\left.C t n n b 1^{\text {flox/flox }}\right)$ littermates. Attempts were made to induce decidualization using both natural (pregnancy) and artificial (intrauterine sesame oil injections during pseudopregnancy; [11]) means in control mice expressing $\beta$-catenin in the stromal compartment, as well as in mutant $A m h r 2^{C r e /+} ; C t n n b 1^{d / d}$ mice. To study 
the proliferative/mitotic effects of steroids on endometrial tissue from control and conditionally mutant female mice, ovariectomies were performed between three and five weeks of age. One week later, female mice were treated subcutaneously with steroid hormones as indicated in the legend of each figure. Tissues were collected at specified times, prepared for paraffin sectioning and analyzed for proliferation (BrdU labeling) and/or mitosis (phospho-histone H3 expression) as described below.

\section{Messenger RNA and protein expression analyses}

Total RNA was extracted from individual samples and reverse transcribed (Superscript II RT; Invitrogen, Carlsbad, CA) with oligo-dT primers following DNase I treatment to eliminate genomic DNA contamination. Standard RT-PCR was then performed for genes of interest using primer sets listed in Table 1. $\beta$-actin mRNA was used as an internal control and a mock RT was also included as a template to confirm the absence of genomic DNA contamination. Quantitative RT-PCR analysis of Gli1, Ptch1, Ihh, Mucland $\beta$-actin mRNA levels, was performed using a Cepheid Smart Cycler II with primers specific for each gene (Table 1) and $Q$ SYBR Green Supermix (Bio-Rad). Relative quantification of mRNA levels was determined in which ratios for each gene was established using $\beta$-actin as a reference gene.

For immunohistochemical and immunofluorescent analyses, whole implantation sites and mechanically decidualized uterine tissues were prepared from paraffin or frozen sections as previously described [11,12]. Frozen uterine tissue sections from Rosa-EYFP transgenic mice were counterstained with DAPI and viewed directly using fluorescence microscopy. Sections processed for immunofluorescence were incubated with anti-total $\beta$-catenin antibodies at a dilution of 1:200 (Abcam) followed by incubation with an Alexafluor 546 conjugated secondary antibody (Invitrogen) and mounting medium containing DAPI.

For immunohistochemical detection of the active form of $\beta$-catenin, phospho-histone H3, ESR1 and progesterone receptor (PGR), paraffin embedded uterine sections were prepared as described elsewhere [11]. Sections were incubated with primary antibody diluted [(1:100 for antiactive $\beta$-catenin (Millipore), 1:2000 for anti-phospho-histone H3 (Upstate Biotechnologies), 1:300 for anti-ESR1 (Santa Cruz) and 1:300 for anti-PGR (Dako)], then incubated with biotinylated secondary antibody (1:500; Santa Cruz Biotechnologies) and horseradish peroxidase-conjugated streptavidin (Vector Laboratories; Burlingame, CA). Sections were exposed to 3,3'-diaminobenzidine (DAB) substrate, counterstained with hematoxylin, dehydrated, and mounted for light microscopy. The mean ratio of mitotic epithelial cells in endometrial tissue sections was established by counting the number of phospho-histone H3-positive cells and dividing by the total number of cells (mean of three tissue sections obtained from three different regions of the uterus) following standard immunohistochemical detection. $\beta$-catenin expression was also assessed by immunofluorescence in primary human endometrial stromal cells (kindly provided by Dr. Bo Rueda, Massachusetts General Hospital) induced to undergo decidualization in vitro by provision of $100 \mu \mathrm{M}$ cAMP, 36 $\mathrm{nM} 17 \beta$-estradiol benzoate, and $1 \mu \mathrm{M} \mathrm{P}_{4}$ for 12 days.

\section{BrdU labeling and analysis of cellular proliferation}

To assess cell proliferation in the individual epithelial and stromal compartments, control and mutant female mice were first ovariectomized at three to five weeks of age and allowed to clear endogenous ovarian-derived sex steroids for at least one week. Female mice then received $E_{2}$ (100 ng s.c. in $100 \mu \mathrm{l}$ sesame oil) on two consecutive days to prime the uterus and six days later began one of the following steroid hormone treatments. For epithelial cell proliferation, female mice received a single s.c. injection of $\mathrm{E}_{2}$ (50 ng in $50 \mu \mathrm{l}$ of sesame oil) $(\mathrm{n}=5$ controls, $\mathrm{n}=3$ mutants). For stromal cell proliferation, female mice were injected with $\mathrm{P}_{4}$ ( $1 \mathrm{mg}$ s.c. in $100 \mu \mathrm{l}$ sesame oil) for three consecutive days and the following day with $\mathrm{E}_{2}+\mathrm{P}_{4}$ (50 ng and $1 \mathrm{mg}$ respectively in $100 \mu \mathrm{l}$ sesame oil)] ( $\mathrm{n}=8$ controls and mutants). Then 16 hrs after the final steroid hormone injection, female mice were treated with $50 \mathrm{mg} / \mathrm{kg}$ body weight 5-bromo-2'-deoxyuridine (BrdU; i.p. in $250 \mu \mathrm{l} \mathrm{sa-}$ line) for 2 hours prior to euthanasia and uterine dissection. Tissues were prepared for paraffin embedding and

Table 1 PCR primers

\begin{tabular}{|c|c|c|c|}
\hline Murine Gene & Primer sequence & Annealing temperature & Cycles \\
\hline Pgr & 5'ATGGTCCTTGGAGGTCGTAA3' 5'CACCATCAGGCTCATCC3' & 60 & 34 \\
\hline Esr1 & 5'CCAAAGCCTCGGGAATG3' 5CTTTCTCGTTACTGCTGG3' & 56 & 33 \\
\hline Esr2 & 5'GGGCCTGTTCGCCAGACTGC3' 5'CAGGGATTTTCTTGGC3' & 56 & 33 \\
\hline Ihh & 5'CGTGCATTGCTCTGTCAAGT3' 5'CTCGATGACCTGGAAAGCTC3' & 56 & 37 \\
\hline Pct1 & 5'CCTCCTTACGGTGGACAAA 3' 5' GCCACATCAAGAGGTTTGGT 3' & 56 & 40 \\
\hline Gli1 & 5'CCTGGTGGCTITCATCAACT3' 5'GTGGTACACAGGGCTGGAGT3' & 56 & 38 \\
\hline$\beta$-actin & 5'GATGACGATATCGCTGCGCTG3' 5'GTACGACCAGAGGCATACAGG3' & 60 & 26 \\
\hline
\end{tabular}


one section (6 $\mu \mathrm{m}$ thick) from three different regions of each uterus were used to assess BrdU incorporation immunohistochemically using a BrdU staining kit (Invitrogen Corporation, Camarillo, CA) per manufacturer's instructions. The mean percentages of BrdU positive cells in the luminal epithelium (LE) and stroma were calculated by establishing a ratio of BrdU positive cells divided by the total number of cells within the luminal epithelium or subluminal stromal compartment.

\section{Experimental replication and statistical analysis}

Each experiment was independently replicated a minimum of three times with different mice in each experiment. Data in graphs represent the mean \pm SEM from replicated experiments. Assignment of mice to each experiment was made randomly. Raw data were analyzed with GraphPad PRISM software (version 4.0) for simple comparisons. Mean values were considered significantly different when $p<0.05$.

\section{Results}

\section{$\beta$-catenin expression during uterine receptivity and} stromal decidualization

Our initial investigation showed that total $\beta$-catenin protein was observed throughout the implantation site on day of pregnancy (DOP) 7.5 (Figure 1A). The honeycomb expression pattern showed that $\beta$-catenin localized to the plasma membranes of decidualized stromal cells of both the antimesometrial and mesometrial compartments, consistent with its role in maintaining adherens function $[13,14]$. Similarly, expression of $\beta$-catenin was observed in primary human decidual cells (Figure 1B), as well as decidual cells of mechanically-induced pseudopregnant female mice on day of pseudopregnancy (DOPP) 6.5 (Figure 1C). We also analyzed whether localization of $\beta$-catenin to the nuclei of stromal cells changed with decidualization and observed that the active, dephosphorylated form of $\beta$-catenin was detected at the initial stages of decidualization on DOP 4.5 in both epithelial and stromal cells (Figure 1E). While the active form of $\beta$-catenin became localized to the membranes, cytoplasm and nuclei of epithelial cells on DOP 4.5 , active $\beta$-catenin localized predominantly to the nuclei of stromal cells undergoing decidualization. This finding supports endocrine-dependent transcriptional and cell cycle regulatory roles for $\beta$-catenin in the stromal compartment as has been previously suggested based on the use of an ovariectomized rat model supplemented with steroid hormones [15]. By DOP 7.5, staining for active $\beta$-catenin was diminished in terminally differentiated decidual cells (Figure 1G). A similar expression profile was observed for active $\beta$-catenin on corresponding days of pseudopregnancy where decidualization was initiated by artificial means (data not shown). $\beta$-catenin was not detected in control sections where primary antibody was omitted (Figure 1D, F, H).
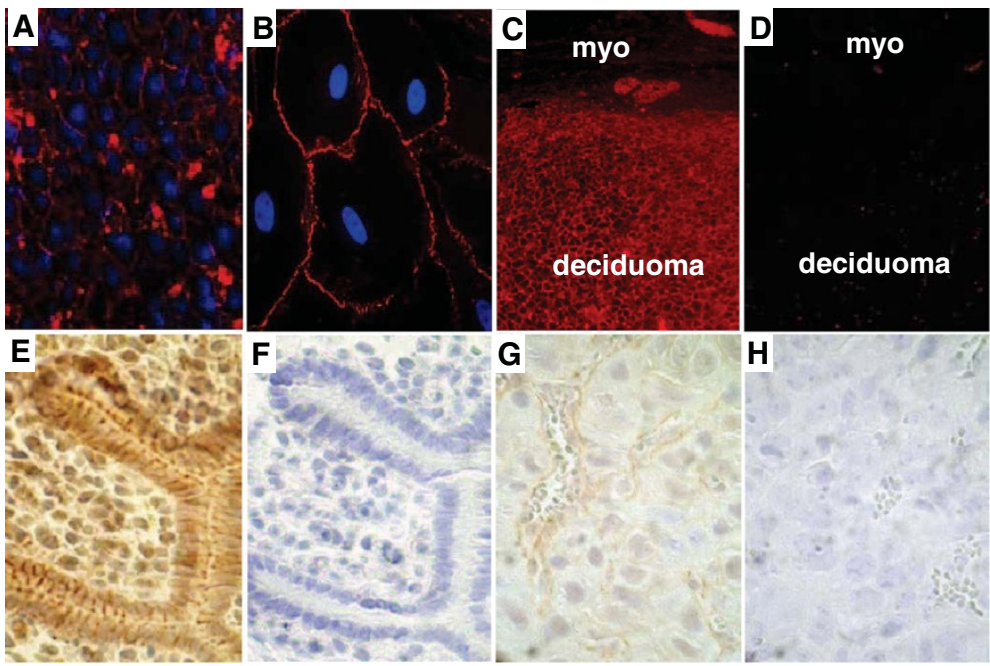

Figure 1 Immunofluorescent detection of $\beta$-catenin during uterine decidualization. Shown are representative images of total $\beta$-catenin immunofluorescent staining in transverse sections of implantation sites obtained on day of pregnancy (DOP) 7.5 (A), decidualized primary human endometrial stromal cells (B) and transverse sections of decidualized uterine tissue from day of pseudopregnancy (DOPP) 6.5 (C, D). Total $\beta$ catenin is expressed primarily at the cell surface of decidual stromal cells through the antimesometrial $(\mathbf{A}, 400 \mathrm{X})$ and mesometrial (data not shown) poles on DOP 7.5, as well as in primary human endometrial stromal cells induced to undergo decidualization (B, 1000X). On DOPP 6.5 $\beta$ catenin is abundantly expressed in the stromal deciduum, but was below the level of detection in the myometrium (C, 200X). Immunohistochemistry of dephosphorylated (i.e., active/nuclear) $\beta$-catenin was present on DOP 4.5 (E, 400X), but not DOP 7.5 (G, 400X). $\beta$-catenin was not detected in control sections stained without primary antibody $(\mathbf{D}, \mathbf{F}, \mathbf{H})$. Representative micrographs from $n=3-5$ independent experiments. 
Stromal $\beta$-catenin is necessary for establishing pregnancy Because $\beta$-catenin expression increased dramatically in uterine stromal cells during decidualization, we hypothesized that this transcriptional co-activator functions to facilitate stromal cell differentiation. Complete $\beta$-catenin deficiency results in embryonic lethality [16]. Mice harboring the anti-Müllerian hormone type II receptor (Amhr2) gene promoter-driven Cre recombinase gene [17] were therefore used to conditionally delete Ctnnb1 when mated with mice harboring floxed Ctnnb1 alleles
[10]. Stromal and decidual cell-specific activity of Cre recombinase was first confirmed using the floxed EYFP reporter mouse. As shown in Figure 2A, EYFP fluorescence was observed throughout the reproductive tract during early pregnancy (DOP 6), as well as in artificially stimulated deciduomal tissue of pseudopregnancy (DOPP 6) of double transgenic Cre recombinase expressing EYFP reporter mice $\left(\right.$ Amhr $2^{\text {Cre } /{ }^{+}} ;$Rosa-EYFP). As anticipated, EYFP was only observed in stromal cells of the endometrium from Amhr $2^{\text {Cre/+ }}$;Rosa-EYFP female mice on postnatal day 13 ,
A
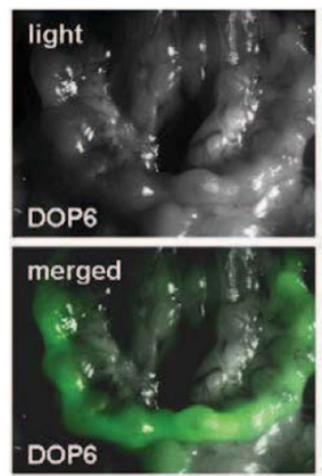

DOP6

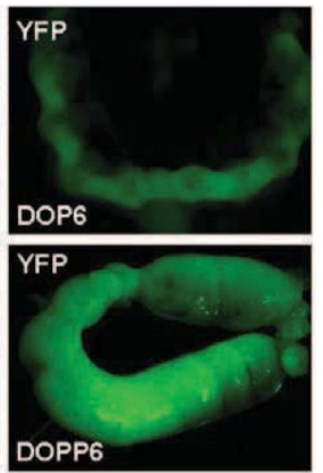

B
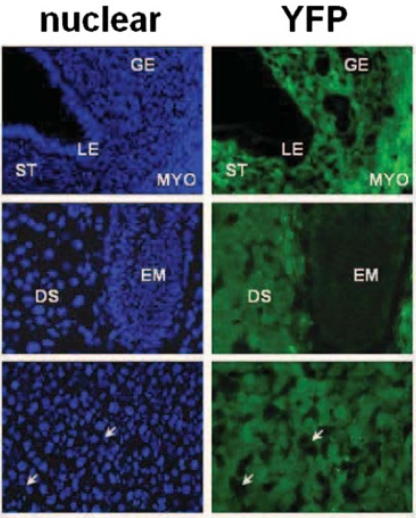

DOP7

(anti)

Cre/YFP
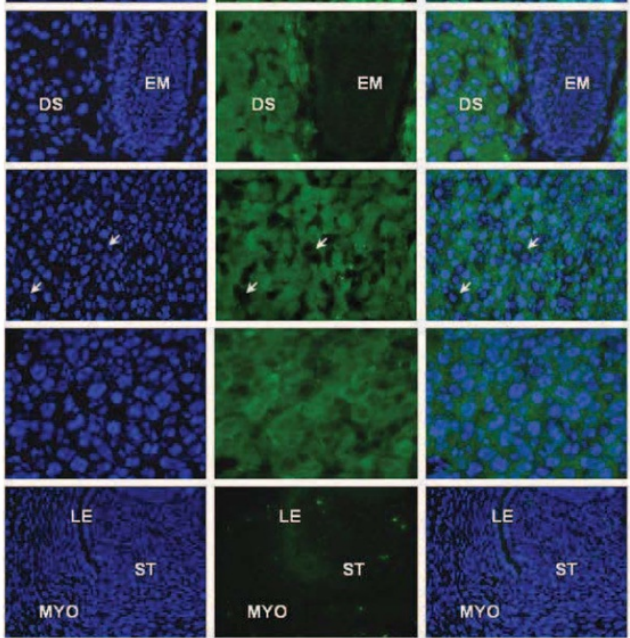

Figure 2 Validating the use of the $A m h r 2^{C r e}$ transgenic mouse for studying gene function during uterine stromal cell decidualization. Amhr2 ${ }^{\mathrm{Cre}}$ transgenic mice were crossed with double floxed yellow fluorescent protein (Cre/EYFP) transgenic mice. (A) At sexual maturity female offspring were bred and implantation sites were observed grossly under fluorescent lighting on day of pregnancy 6 (DOP6, upper right and lower left panels) or day of pseudopregnancy 6 (DOPP6, lower right panel). (B) Direct fluorescent microscopy was used to assess frozen histological sections on postnatal day 13 (pnd13), DOP7 and DOPP7. Note that EYFP was present only in the stroma (ST) and myometrium (MYO) on pnd13 and DOP7 and absent in the luminal (LE) and glandular (GE) epithelia (pnd13). Likewise, EYFP was not detected in certain cells at the mesometrial pole that are presumably natural killer and endothelial cells (white arrows). EYFP was expressed at both the antimesometrial (anti) and mesometrial (meso) poles on DOP7. No EYFP was observed in EYFffloxflox single transgenic mice (EYFP) that lack cre recombinase expression (B, lower panels). All images taken at 400X magnification. DS, decidualized stroma; EM, embryo. 
DOP 7 and DOPP 7, while vascular endothelial (eg., DOP 7 mesometrium) and epithelial cells were devoid of EYFP fluorescence (Figure 2B).

We next generated Amhr2 $2^{C r e /+}{ }_{C t n n} b 1^{d / d}$ double transgenic conditionally null mice and used immunofluorescence microscopy to confirm restricted deletion of $\beta$-catenin from the stromal, but not epithelial compartment. Total $\beta$-catenin was observed in epithelia of both Ctnnb1 $1^{\text {flox/flox }}$ control (Figure 3A) and Amhr2 $2^{C r e /+}$; $C$ tnnb1 $^{d / d}$ mutant (Figure $3 \mathrm{~B}$ ) uteri, as well as in the sub-luminal stromal compartment of $C \operatorname{tnn} b 1^{\text {flox/flox }}$ uteri. Uterine tissues from control and mutant female mice maintained equitable potential to respond to female sex steroids in that they express similar levels of classical sex steroid hormone receptors based on immunohistochemical detection of ESR1 (Figure 3E, F) and PGR (Figure 3G, H),
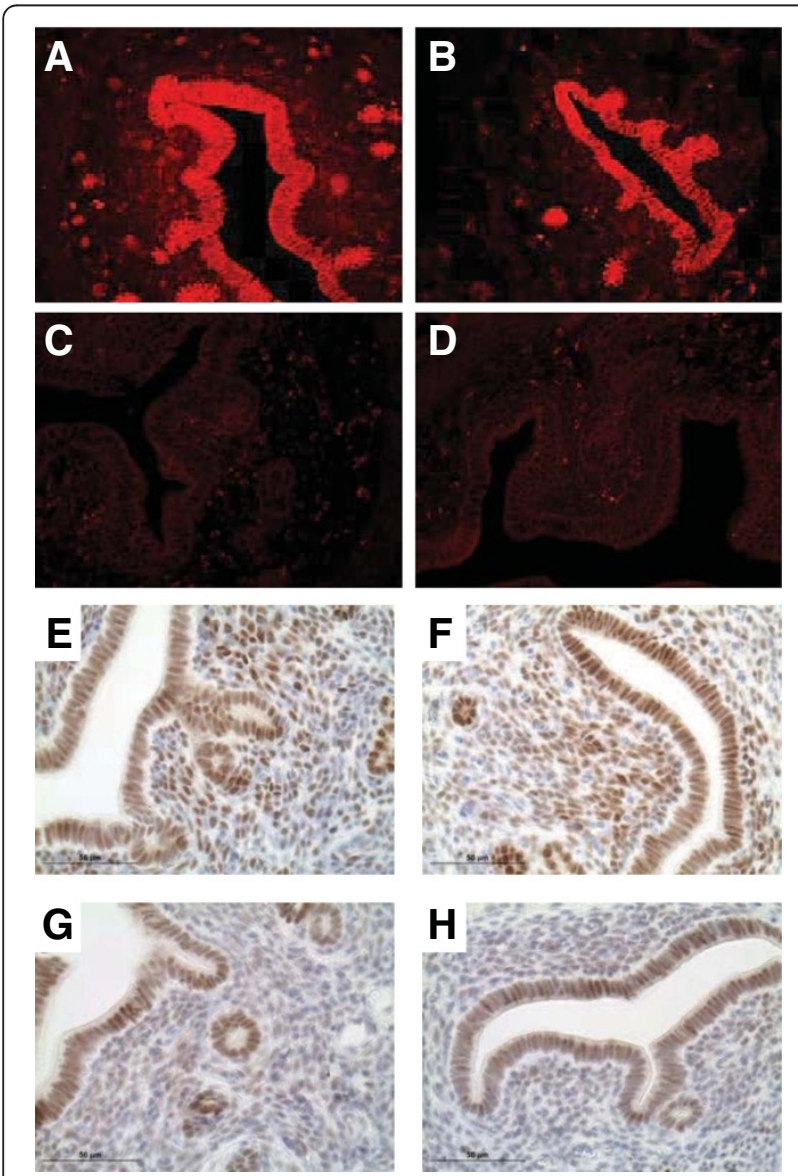

Figure 3 Equitable steroid hormone receptor expression in control and mutant uteri. Immunofluorescent detection of total $\beta$ catenin in $\mathrm{Ctnnb} 1^{\text {flox/flox }}$ control $(\mathbf{A})$ and $\mathrm{Amhr} 2^{\mathrm{Cre} / \mathrm{H}} ; \mathrm{Ctnnb}^{\mathrm{d} / \mathrm{d}}$ mutant (B) uteri (200X). Total $\beta$-catenin was not detected in sections where primary antibody was omitted (C, D). Immunohistochemical detection of ESR1 in control (E) and mutant uteri $(\mathbf{F})$, as well as PGR protein expression in control $(\mathbf{G})$ and mutant $(\mathbf{H})$ uteri. Representative micrographs from $n=3$ independent experiments. as well as mRNA expression of each receptor as determined by semi-quantitative RT-PCR (data not shown).

Amhr $2^{C r e /+}$;Ctnnb1 ${ }^{d / d}$ female mice are infertile due in part to incomplete development of the oviduct $[18,19]$. To study the impact of $\beta$-catenin deficiency within the stromal compartment on uterine function, decidualization was induced artificially in female mice bred to vasectomized male mice on day of pseudopregnancy (DOPP) 4. This approach circumvented the need for an intact oviduct and embryo deposition into the uterus for the initiation of decidualization. While Ctnnb1 $1^{\text {flox/flox }}$ control mice showed normal decidualization reaction 36$72 \mathrm{~h}$ after induction, uteri from $\mathrm{Amhr} 2^{\mathrm{Cre} /{ }^{+}} ; \mathrm{Ctnn}_{\mathrm{b}} 1^{\mathrm{d} / \mathrm{d}}$ female mice could not be stimulated to undergo decidualization (Figure 4A). Histological analysis confirmed this finding (Figure $4 \mathrm{~B}-\mathrm{C}$ ). To rule out the possibility that uteri from $\mathrm{Amhr} 2^{\mathrm{Cre} /{ }^{+}} ; \mathrm{Ctnn} b 1^{d / d}$ mice fail to decidualize due to insufficient endogenous ovarian steroid hormone synthesis, ovariectomized Ctnnb1 $1^{\text {flox/flox }}$ control and Amhr2 $2^{\mathrm{Cre} /+}$; $C$ tnnb1 ${ }^{d / d}$ mice were exposed to exogenous steroids in a regimen that mimicked early pregnancy to induce artificial decidualization [20]. Steroid supplemented control mice show normal decidualization reactions at 36-72 $\mathrm{h}$ based on histological examination (Figure 4E), but uteri from $A m h r 2^{C r e /+}$;Ctnnb1 ${ }^{d / d}$ mice were again incapable of undergoing decidualization (Figure 4D). These findings indicate that stromal $\beta$-catenin is essential for uterine decidualization.

A role for stromal $\beta$-catenin in steroid hormone signaling Decidualization requires exposure of the uterus first to $\mathrm{E}_{2}$ followed by $\mathrm{P}_{4}$. Since decidualization failed in Amhr $2^{\mathrm{Cre} /+}$;Ctnnb1 ${ }^{d / d}$ mice, we next studied whether the loss of $\beta$-catenin interfered with steroid hormone signaling in control and mutant female mice. Gross (Figure 5A) and histological (Figure 5B) examination of uteri exposed to a single injection of $E_{2}$ (100 ng, 24 h) revealed that uteri from both $C \operatorname{tnn} b 1^{\text {flox/flox }}$ control and Amhr $2^{\mathrm{Cre} /{ }_{+}}$; Ctnnb1 ${ }^{d / d}$ mice become edematous, a normal physiological response to $\mathrm{E}_{2}$. A more subtle response to $\mathrm{E}_{2}$ was observed in $\mathrm{Amhr} 2^{\mathrm{Cre} /+} ; \mathrm{Ctnnb1} 1^{\text {d/d }}$ uteri, but this likely stems from reduced early postnatal growth of uterine mesenchyme rather than from a lack of an $\mathrm{E}_{2}$ signaling cascade. This can be seen when comparing uteri from Ctnnb1 $1^{\text {flox/flox }}$ and $A m h r 2^{C r e /+}$; $C \operatorname{cnnb1} 1^{d / d}$ mice exposed to vehicle (Figure $5 \mathrm{~B}$ ) and is supported by an equal number of $E_{2}$-induced epithelial cell mitoses (i.e., phospho-histone $\mathrm{H} 3$ immunostaining) in control and mutant uteri (Figure 5C) suggesting normal $E_{2}$-induced epithelial cell proliferation. This experiment was then repeated using the BrdU labeling (i.e., marker of proliferation) approach and it was again determined that $\beta$-catenin-deficiency within the stromal compartment did not compromise epithelial cell proliferation 


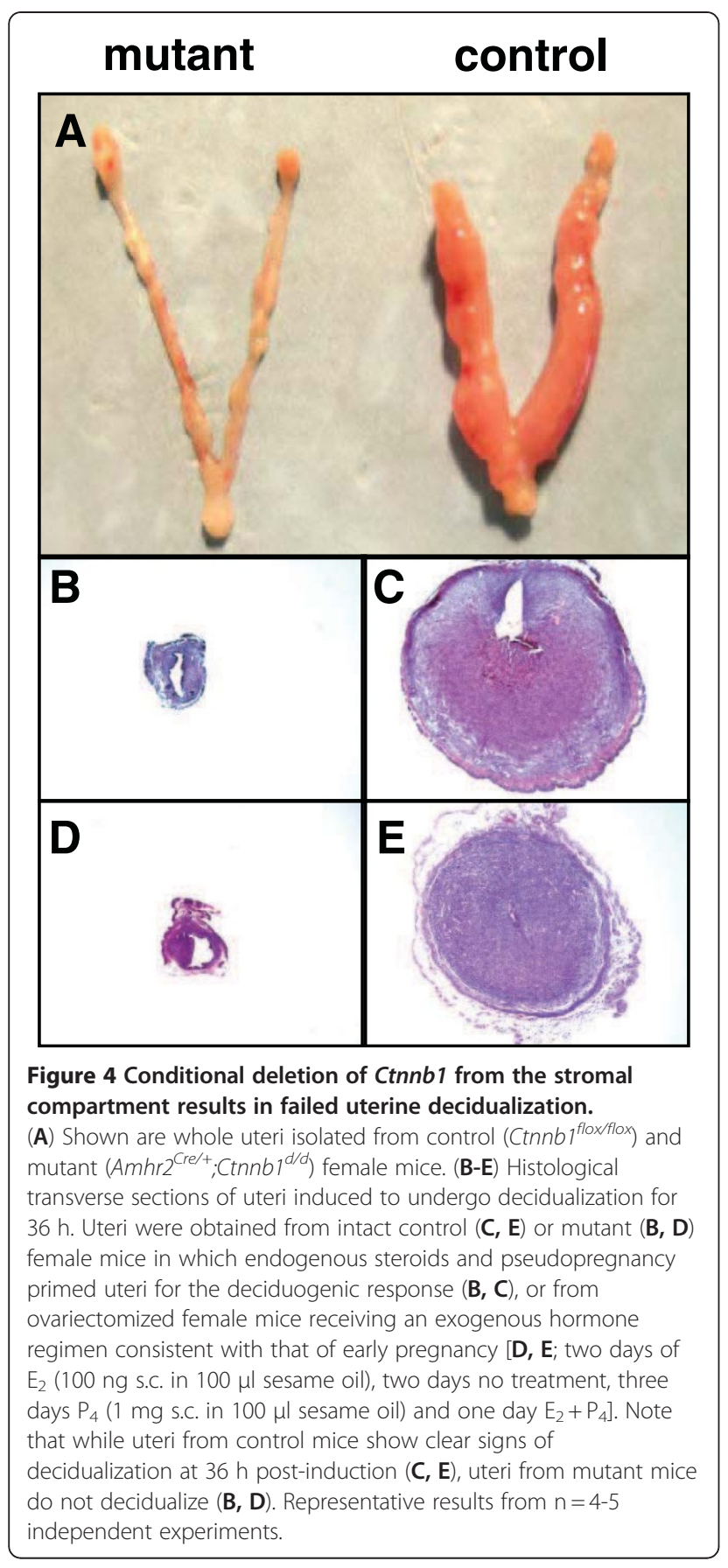

(Figure 5D-F). Finally, control and mutant female mice were exposed to $E_{2}$ and $P_{4}$ in a regimen consistent with early pregnancy to determine if stromal cell proliferation was altered in the endometria of conditionally null Ctnnb1 female mice. As shown in Figure 5G-I, stromal $\beta$-catenindeficiency did not significantly reduce stromal cell proliferation in response to steroid hormones. Collectively, these results suggest that the lack of $\beta$-catenin in endometrial stroma does not materially affect steroid hormone-induced cellular proliferation or stromal imbibition.
We next examined whether the failure of $\mathrm{Amhr} 2^{\mathrm{Cre} /+}$; $C t n n b 1^{d / d}$ mice to undergo decidualization could be due to disruption of other critical signaling pathways that coordinate mesenchymal-to-epithelial communication. Mechanical decidualization was performed on 4-5 week old ovariectomized control and mutant mice for microarray analyses of $\mathrm{P}_{4}$-induced genes. Following treatment with a hormone regimen consistent with early pregnancy, the mRNAs of many known targets of $\mathrm{P}_{4}$ signaling during early pregnancy were disrupted in mutant uteri. One pathway in particular, the Indian hedgehog signaling pathway (Gli1, Ptch1, Ihh), was markedly reduced in mutant uteri (Figure 6A-C). In contrast, Muc1, a gene that is down-regulated at the time of embryo attachment and is a $\mathrm{P}_{4}$ target gene, remained elevated in mutant, but not control, uteri (Figure 6D). Interestingly, histological evaluation of transverse uterine sections $18 \mathrm{~h}$ after the final injection of combined $\mathrm{E}_{2}$ and $\mathrm{P}_{4}$ revealed that while control uteri showed the expected simple columnar epithelium and general tissue architecture (Figure 7A-B), uteri from 3/9 (33\%)

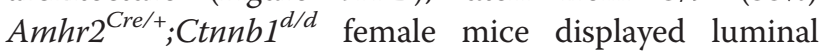
epithelial metaplasia containing cystic structures and marked recruitment of leukocytes, particularly into the luminal space (Figure 7C-D). This observation prompted us to evaluate serial sections from control and mutant uteri exposed to $E_{2}$ for $24 \mathrm{~h}$. Here, regions of bilaminar stratification were observed within the luminal epithelium in $66 \%(4 / 6)$ of the mutant uteri (Figure 7E). Consistent with previous findings in which Ctnnb1 was deleted using Pgr-cre [21], the posteriorization of the uterus shown here suggests that stromal $\beta$-catenin is necessary for maintenance of simple epithelial architecture within the uterus in response to $E_{2}$.

\section{Discussion}

Adult endometrial functions are temporally regulated by sex steroid hormones that require interplay between the epithelial and underlying stromal compartments. Ovarian-derived $E_{2}$ generated during each estrous/menstrual cycle stimulates epithelial cell proliferation. The proliferative epithelial response to $E_{2}$ is largely an indirect event that involves stromal release of epithelial mitogens such as IGF-1 [22,23]. It was recently established through conditional mutagenesis studies that stromalderived ESR1 is fundamental for directing epithelial cell proliferation, while epithelial ESR1 is dispensable [24]. In turn, ovarian $\mathrm{P}_{4}$ completely abolishes $\mathrm{E}_{2}$-induced epithelial cell proliferation in vivo [25]. Clinically, $\mathrm{P}_{4}$ is applied prophylactically in some settings to treat estrogen-dependent endometrial cancer and to alleviate potential complications during hormone replacement therapies that can arise due to the unopposed actions of estrogens. These fundamental actions of $\mathrm{E}_{2}$ and $\mathrm{P}_{4}$ 


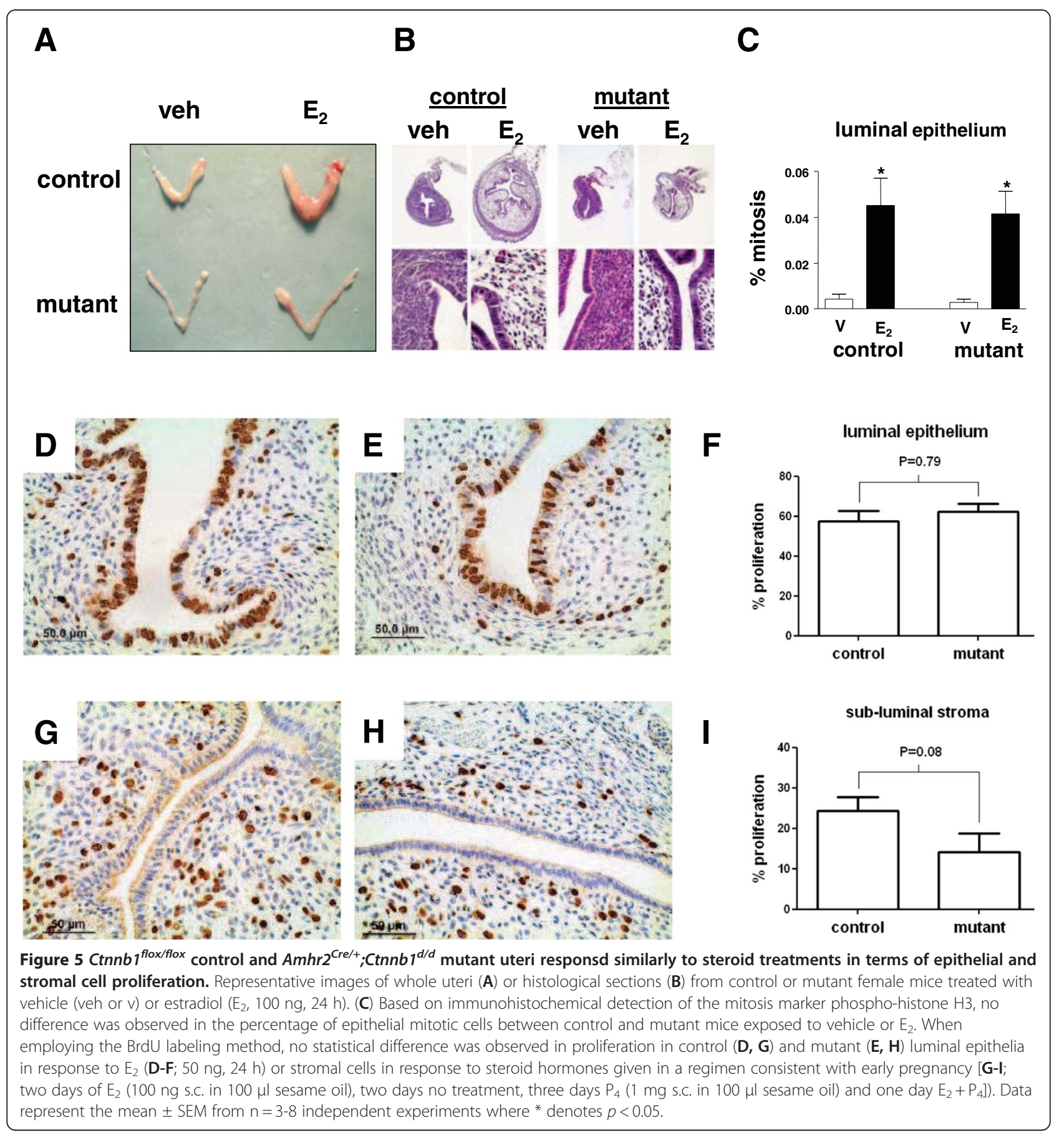

within the endometrium are further validated in pharmacological studies where steroid hormone actions are attenuated, as well as through the use of mutant mice deficient in expression of ESR1 and PGR.

$A m h r 2^{C r e /+} ; C t n n b 1^{d / d}$ mice are infertile, which engenders two previously unappreciated points for consideration. First, that deletion of Ctnnb1 from the stromal, but not epithelial, compartment results in failed decidualization, suggests that this transcriptional co-activator mediates steroid hormone actions in the endometrium that are critical for fertility. Further investigation is needed to determine if $\beta$-catenin interacts in parallel with PGR, forming a complex that in turn regulates expression of genes in stromal tissue whose encoded products contribute to decidualization. Precedence for the convergence of $\beta$-catenin and steroid hormone signaling pathways has been established in the uterus. Alternatively, the PGR and $\beta$-catenin signaling pathways 


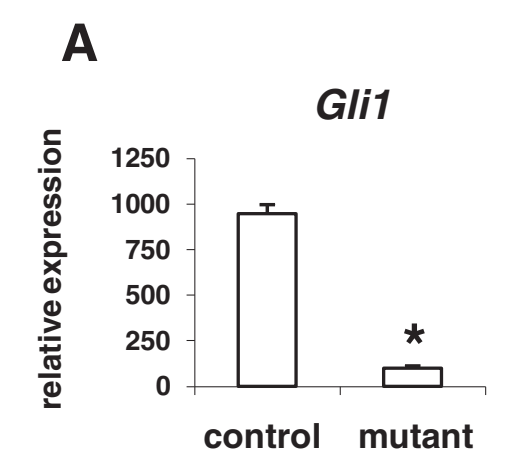

B
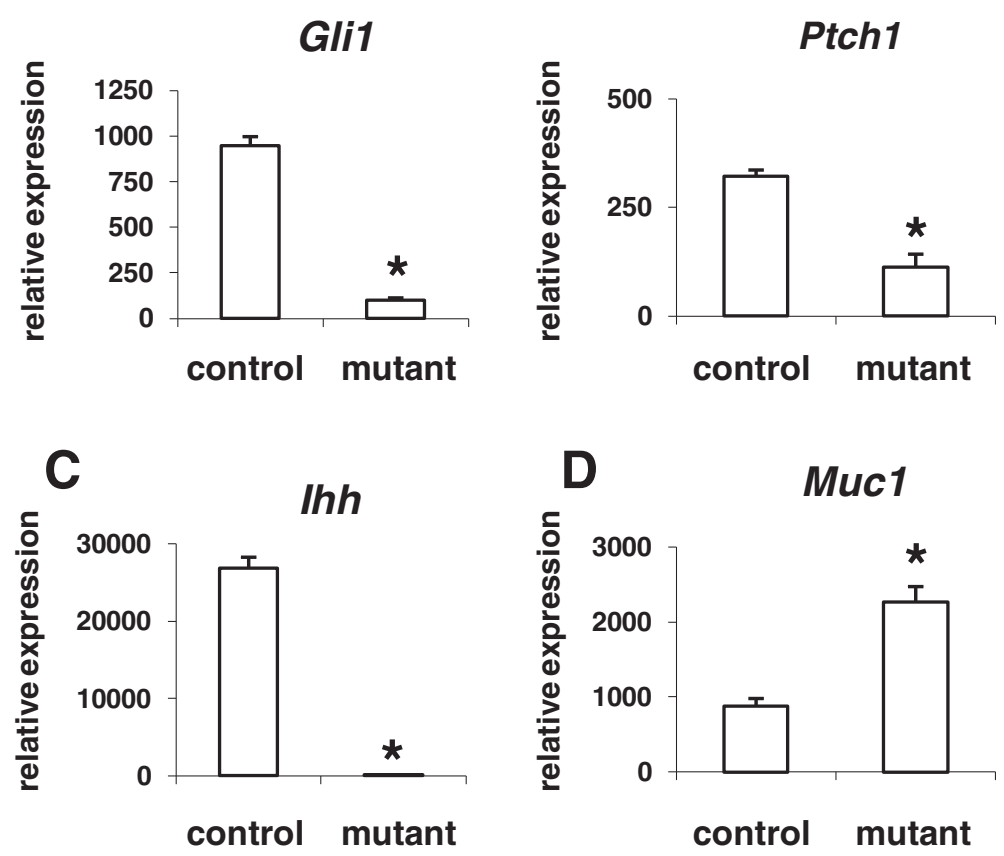

Figure 6 Real time RT-PCR demonstrating differential mRNA expression of genes critical for embryo implantation. Control and mutant uteri were obtained from female mice treated with a steroid hormone regimen consistent with early pregnancy [two days of $E_{2}$ (100 ng s.c. in $100 \mu \mathrm{l}$ sesame oil), two days no treatment, three days $P_{4}\left(1 \mathrm{mg}\right.$ s.C. in $100 \mu \mathrm{l}$ sesame oil) and one day $\left.\left.E_{2}+P_{4}\right]\right)$. Shown are real time RT-PCR results for Gli1 (A), Ptch1 (B), Ihh (C) and Muc1 (D). Data represent mean + SEM of $\mathrm{n}=4$ independent experiments.

may work in series where PGR results in activation of another pathway, such as WNTs that in turn utilize $\beta$ catenin function. This scenario is supported by recent findings where WNT4 was shown to be a key regulator of normal postnatal uterine development and progesterone signaling during embryo implantation and decidualization [26]. Additional evidence for a PGR- $\beta$-catenin interaction comes from in vitro decidualization studies using human stromal cells where PGR expression was shown to be essential for nuclear translocation of $\beta$-catenin [27].

The second point for consideration is that stromal $\beta$-catenin is necessary for transcriptional regulation of both stromal and epithelial factors that are important for initiating decidualization and embryo attachment. Stromal $\beta$-catenin-deficiency results in failed up-regulation of Ihh in the epithelium, as well as Ptch1 and Gli1 in the stroma suggesting that stromal $\mathrm{P}_{4}$ signaling mediates events not only in the stromal compartment, but also in the overlying epithelium. It is concluded from this investigation that stromal $\beta$-catenin is a component of the signaling conduit through which $\mathrm{P}_{4}$ coordinates events in the overlying epithelium. Recent tissue recombination studies involving the use of wild type and Pgr-null stroma and/or epithelia support this concept [28]. Here, Simon et al. established that neonatal tissue recombinants containing wild type epithelium and PGR-deficient stroma were unable to show elevated levels if Ihh in the epithelium in response to $\mathrm{P}_{4}$ treatment [28].

Some studies have suggested direct inhibitory actions of $\mathrm{P}_{4}$ on $\mathrm{E}_{2}$-induced epithelial cell proliferation. During the time of embryo implantation on day 4 of pregnancy in mice the epithelium does not express PGR despite observation of clear progestational response on the epithelium $[29,30]$. How then does $\mathrm{P}_{4}$ signal in the epithelium in the absence of PGRs? The "progestamedin hypothesis" suggests that $\mathrm{P}_{4}$-induced paracrine factors secreted from the stromal compartment indirectly regulate $\mathrm{P}_{4}$ actions on the epithelium [30]. It was recently established that $\mathrm{E}_{2}$-induced epithelial proliferation is suppressed by $\mathrm{P}_{4}$ actions in the stromal compartment involving a HAND2dependent mechanism [31]. Progesterone induces the transcriptional inhibitor HAND2, which in turn suppresses specific members of the fibroblast growth factors family in the stromal compartment [31]. Our study places $\beta$-catenin squarely in the middle of $\mathrm{P}_{4}$-dependent mesenchymal-to-epithelial signaling during the initiation of maternal:embryo interaction.

A number of signaling factors and down-stream transcription factors have been identified through mutant mouse studies as critical components coordinating decidualization. Some of these include IHH, WNT4, 

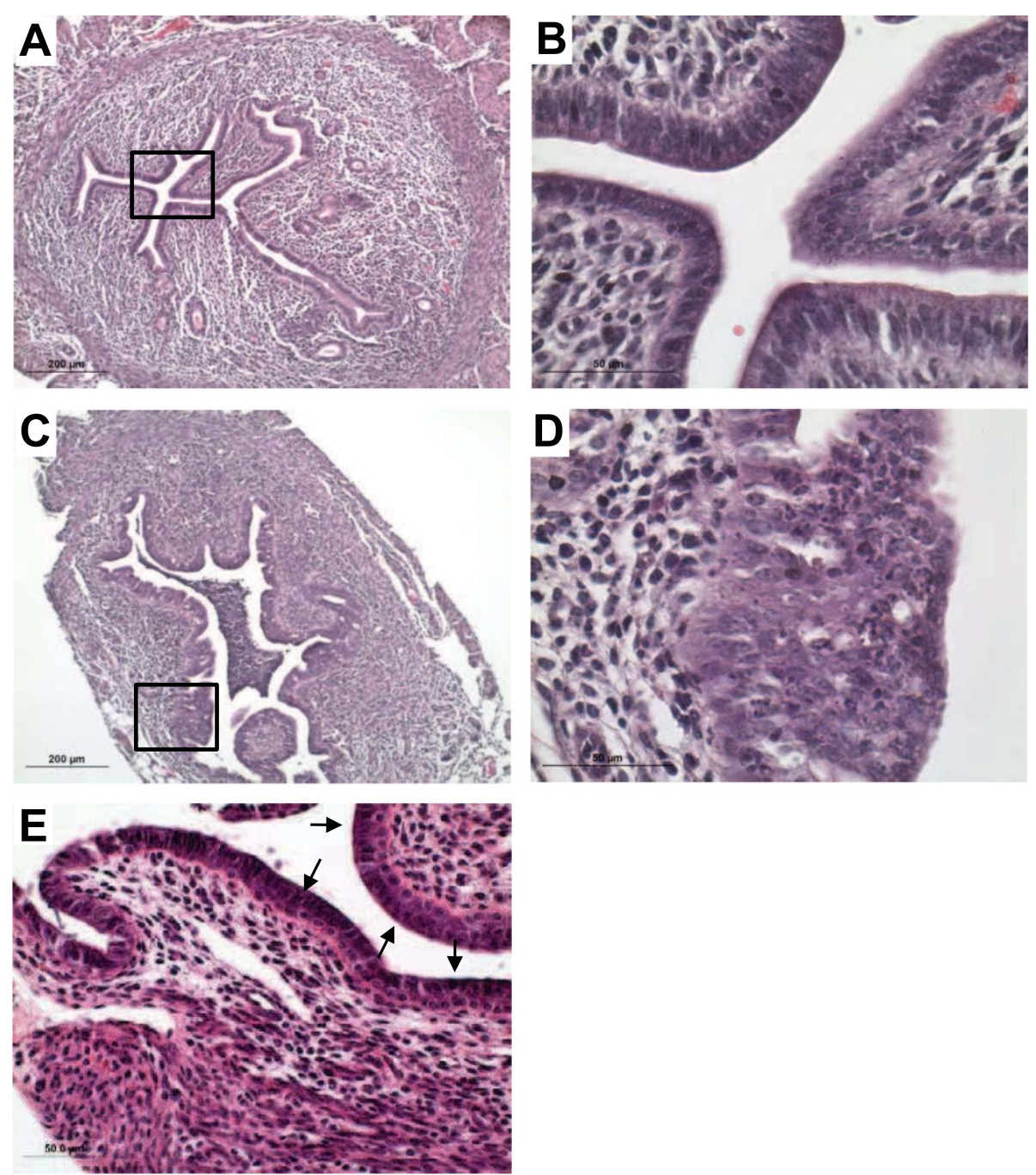

Figure 7 Stromal $\beta$-catenin deficiency results in development of luminal metaplastic lesions in $A m h r 2^{\mathrm{Cre} /{ }^{+}} ; \mathrm{Ctnnb} 1^{\mathrm{d} / \mathrm{d}}$ mutant uteri following steroid hormone treatment. Hematoxylin and eosin stained sections from Ctnnb $1^{\text {flox flox }}$ control $(\mathbf{A}, \mathbf{B})$ and $\mathrm{Amhr} 2^{\mathrm{Crel+}+} ; \mathrm{Ctnnb} 1^{d / d}$ mutant $(\mathbf{C}, \mathbf{D})$ uteri following treatment of ovariectomized female mice with a steroid hormone regimen consistent with early pregnancy [two days of $E_{2}\left(100 \mathrm{ng}\right.$ s.c. in $100 \mu \mathrm{l}$ sesame oil), two days no treatment, three days $P_{4}\left(1 \mathrm{mg}\right.$ s.c. in $100 \mu \mathrm{l}$ sesame oil) and one day $E_{2}+P_{4}$ ].

(E) Regions of bilaminar stratification (black arrows) were observed within the luminal epithelium in $66 \%(4 / 6)$ of the mutant uteri following $E_{2}$ (100 ng, 24 h) treatment. Representative images from $n=6-9$ independent experiments.

HOXA10, HOXA11, Src-kinase, BMP2 and COUP-TFII reviewed in [32]. Indian hedgehog localizes to the epithelium in response to $\mathrm{P}_{4}$ at the time of embryo implantation, and tissue restricted deletion of the gene using the PgrR-Cre mouse model results in failed decidualization [33-35]. From our study it is clear that transcription of members of the IHH pathway is reduced in $\mathrm{Amhr} 2^{\mathrm{Cre} /+}$; Ctnnb1/d $1^{d / d}$ uteri in response to steroid hormones; however, additional functional studies are necessary to determine exactly how $\beta$-catenin is linked to the $\mathrm{IHH}$ signaling pathway.

Uteri from $\mathrm{Amhr} 2^{\mathrm{Cre} / \mathrm{+}} ; \mathrm{Ctnnb}^{d / d}$ mice are smaller in size than control uteri, which could confound the interpretation of these results. However, four lines of evidence suggest that the failure of $A m h r 2^{\mathrm{Cre} /+} ; \mathrm{Ctnn} b 1^{d / d}$ uteri to decidualize stems from disruption of steroid hormone receptor signaling rather than from altered prenatal or early postnatal uterine development. First, expression studies reveal that uteri from $\mathrm{Amhr} 2^{\mathrm{Cre} /+} ; \mathrm{Ctnnb1}^{d / d}$ mice have the potential to respond normally to $\mathrm{E}_{2}$ and $\mathrm{P}_{4}$ in that uterine mRNA and protein levels of ESR1 and PGR do not differ between control and mutant female mice. Second, uteri from control and mutant female mice display a normal response to $E_{2}$, at least in terms of epithelial proliferation and stromal imbibition. Since the stromal compartment mediates the proliferative response in the epithelium, our findings indicate that the uterine stromal compartment of $\mathrm{Amhr} 2^{\mathrm{Cre} /{ }^{+}} ; \mathrm{Ctnnb}^{d / d}$ mice is fully 
capable of disseminating proliferative signals to the epithelium. Third, the actions of $\mathrm{P}_{4}$ are not completely ablated in the uteri of $A m h r 2^{C r e /+} ; C t n n b 1^{d / d}$ mice, since several genes previously shown to be targets of $\mathrm{P}_{4}$ action show the expected pattern of expression. For instance, Hmga2 (high mobility group AT-hook 2), Cdkl1 (cyclin-dependent kinase-like 1), and Ldb2 (LIM domain binding 2) were shown to be down-regulated by $\mathrm{P}_{4}$ treatment in vivo [36]. Based on our microarray analysis each of these genes was down-regulated similarly in control Ctnnb $1^{\text {flox/flox }}$ and mutant $A m h r 2^{C r e /+}$;Ctnnb1 ${ }^{d / d}$ uteri in vivo (data not shown). Conversely, S100a6 (calcyclin), Irg-1 (immune responsive gene-1) and Fst (follistatin), three genes shown to be upregulated by $\mathrm{P}_{4}$ [37], were equitably up-regulated in Ctnnb1 $1^{\text {flox/flox }}$ and Amhr $2^{\text {Cre/+}} ; C$ tnnb $1^{d / d}$ uteri (data not shown). Fourth, indifferent stromal cell proliferation was observed in response to a hormone regimen consistent with early pregnancy. This suggests that the proliferative stromal cell response to $\mathrm{P}_{4}$ is not dependent upon $\beta$-catenin. In sum, these findings indicate that $\beta$-catenin deficiency in the stromal compartment of $A m h r 2^{C r e /+} ; C t n n b 1^{d / d}$ uteri results in aberrant gene expression of a specific cassette of $\mathrm{P}_{4}$-dependent genes, several of which belong to the $\mathrm{IHH}$ signaling cascade, but that other $\mathrm{P}_{4}$ responses are normal.

Two functional studies were previously published on $\beta$-catenin in the uterus. In the first, $\beta$-catenin activity was indirectly assessed through the use of Tcf/Lef-LacZ transgenic mice [38]. Here, $\beta$-galactosidase activity was used to identify coupling of $\beta$-catenin with the TCF/LEF transcriptional complex in situ. Based on this model, $\beta$ catenin activity was observed in the luminal epithelium and circular smooth muscle, an event that required the presence of an embryo. It was concluded that $\beta$-catenin was no longer active by late DOP5. However, $\beta$-catenin activity was defined by its ability to activate the Tcf/LefLacZ transgene, and $\beta$-catenin function was not addressed using deletional analysis (e.g., gene knockdown or mutant mice deficient in $\beta$-catenin). Additionally, while we and others [14] have since demonstrated the presence of active (i.e., dephosphorylated and nuclear) $\beta$-catenin in decidualizing stromal cells, Mohamed et al. were unable to detect transcriptional activity for the TCF/LEF complex in the stromal compartment, suggesting $\beta$-catenin may regulate gene expression within the stromal compartment by a TCF/LEF-independent mechanism.

More recently, Jeong et al. used the Pgr-Cre transgenic mouse line to delete $\beta$-catenin from PGR-expressing tissues, including all compartments of the uterus [21]. Using this model system, $\beta$-catenin deficiency in the entire uterus resulted in pleiotropic effects leading to infertility, most likely because of the inability of stromal cells to terminally differentiate and $\mathrm{E}_{2}$-induced morphological defects. The design, and therefore the conclusion, of our study differ to some extent from this previous report. First, while uteri from $A m h r 2^{C r e /+} ; C t n n b 1^{d / d}$ female mice lack expression of $\beta$-catenin in the myometrial and stromal compartments, as with the Pgr-Cre model, expression of $\beta$ catenin was retained in luminal and glandular epithelia using the Amhr2 ${ }^{C r e}$ mouse line. Second, deletion of $\beta$-catenin in all compartments of the uterus resulted in metaplastic formation of the luminal epithelium in the intact mouse [21]. Analysis of the ovaries indicated that ovarian function was preserved. Jeong et al., concluded that $\beta$-catenin deficiency in the epithelium was the source of the metaplastic phenotype. This conclusion is well justified in that mutations in the human Ctnnb1 gene are commonly associated with endometrial hyperplasia. Although our data does not rule out control of epithelial metaplasia by epithelial $\beta$ catenin, they indicate that, since $A m h r 2^{C r e /+} ; C \operatorname{tnn} b 1^{d / d}$ mutant uteri also develop metaplasia, albeit with reduced severity and incidence, the lack of $\beta$-catenin in stroma alone can dictate formation of epithelial metaplasia. As with $\beta$-catenin, deletion of APC, a component of the $\beta$ catenin signaling pathway, from the uterine stromal compartment results in a more severe phenotype where endometrial hyperplasia and carcinogenesis are observed [39].

\section{Conclusion}

Because $\beta$-catenin is connected to a multitude of cellular processes, we investigated the functional requirement of $\beta$-catenin in the stromal compartment of the endometrium for decidualization and responsiveness to steroid hormones. Our findings indicate that $\beta$-catenin is essential for early events in the terminal differentiation of uterine stromal cells. While it is well established that the stromal compartment indirectly coordinates epithelial cell proliferation through production of paracrine growth factors, deletion of stromal $\beta$-catenin did not alter $E_{2}$-stimulated epithelial cell mitosis. Our study also provides evidence that the stromal compartment, through activation of $\beta$-catenin, mediates as least some of the actions of $\mathrm{P}_{4}$ on the epithelium. It will now be important to delineate upstream signaling pathways that activate stromal $\beta$ catenin and to identify $\beta$-catenin target genes that are necessary for disseminating steroid hormone actions on the epithelium, in addition to its role in decidualization within the stromal compartment.

\section{Competing interests}

None of the authors have competing interests.

\section{Authors' contributions}

LZ completed most of the IHC and RT-PCR and some of the decidualization and histology experiments. AP completed experiments centered on progesterone and estrogen signaling, proliferative responses, receptor expression analyses, as well as some of the decidualization experiments. She also participated in drafting the manuscript. $L Z$ assisted with $\mathrm{HC}$ and animal husbandry. JT provided mice for these experiments and contributed to the experimental design and writing. JP was involved in all aspects of these 
studies and drafted the manuscript. All authors participated in editing and revising the manuscript. All authors read and approved the final manuscript.

\section{Acknowledgments}

This work was supported in part by NIH HD052701 and HD066297.

\section{Author details}

${ }^{1}$ Vincent Center for Reproductive Biology, Vincent Obstetrics and Gynecology Service, Massachusetts General Hospital/Harvard Medical School, Boston, Massachusetts 02114, USA. ²Department of Animal Sciences, Center for Reproductive Biology, Washington State University, Pullman, WA 99164, USA.

Received: 16 April 2012 Accepted: 4 September 2012

Published: 7 September 2012

\section{References}

1. Kurita T, Cooke PS, Cunha GR: Epithelial-stromal tissue interaction in paramesonephric (Mullerian) epithelial differentiation. Dev Biol 2001, 240:194-211.

2. Abrahamsohn PA, Zorn TM: Implantation and decidualization in rodents. $J$ Exp Zool 1993, 266:603-628.

3. Hewitt SC, Harrell JC, Korach KS: Lessons in estrogen biology from knockout and transgenic animals. Annu Rev Physiol 2005, 67:285-308.

4. O'Brien JE, Peterson TJ, Tong MH, Lee EJ, Pfaff LE, Hewitt SC, Korach KS, Weiss J, Jameson JL: Estrogen-induced proliferation of uterine epithelial cells is independent of estrogen receptor alpha binding to classical estrogen response elements. J Biol Chem 2006, 281:26683-26692.

5. Hou X, Tan Y, Li M, Dey SK, Das SK: Canonical Wnt signaling is critical to estrogen-mediated uterine growth. Mol Endocrinol 2004, 18:3035-3049.

6. Ray S, Xu F, Wang H, Das SK: Cooperative control via lymphoid enhancer factor $1 / \mathrm{T}$ cell factor 3 and estrogen receptor-alpha for uterine gene regulation by estrogen. Mol Endocrinol 2008, 22:1125-1140.

7. Grigoryan T, Wend P, Klaus A, Birchmeier W: Deciphering the function of canonical Wnt signals in development and disease: conditional loss- and gain-of-function mutations of beta-catenin in mice. Genes Dev 2008, 22:2308-2341

8. Mikels AJ, Nusse R: Wnts as ligands: processing, secretion and reception. Oncogene 2006, 25:7461-7468.

9. Srinivas S, Watanabe T, Lin CS, William CM, Tanabe Y, Jessell TM, Costantini F: Cre reporter strains produced by targeted insertion of EYFP and ECFP into the ROSA26 locus. BMC Dev Biol 2001, 1:4.

10. Brault V, Moore R, Kutsch S, Ishibashi M, Rowitch DH, McMahon AP, Sommer L, Boussadia O, Kemler R: Inactivation of the beta-catenin gene by Wnt1-Cre-mediated deletion results in dramatic brain malformation and failure of craniofacial development. Development 2001, 128:12531264.

11. Kashiwagi A, DiGirolamo CM, Kanda Y, Niikura Y, Esmon CT, Hansen TR, Shioda T, Pru JK: The postimplantation embryo differentially regulates endometrial gene expression and decidualization. Endocrinology 2007, 148:4173-4184.

12. Szotek PP, Chang HL, Zhang L, Preffer F, Dombkowski D, Donahoe PK, Teixeira J: Adult mouse myometrial label-retaining cells divide in response to gonadotropin stimulation. Stem Cells 2007, 25:1317-1325.

13. Gavert N, Ben-Ze'ev A: Beta-catenin signaling in biological control and cancer. J Cell Biochem 2007, 102:820-828.

14. Herington JL, Bi J, Martin JD, Bany BM: Beta-catenin (CTNNB1) in the mouse uterus during decidualization and the potential role of two pathways in regulating its degradation. J Histochem Cytochem 2007, 55:963-974.

15. Rider V, Isuzugawa K, Twarog M, Jones S, Cameron B, Imakawa K, Fang J: Progesterone initiates Wnt-beta-catenin signaling but estradiol is required for nuclear activation and synchronous proliferation of rat uterine stromal cells. J Endocrinol 2006, 191:537-548.

16. Haegel H, Larue L, Ohsugi M, Fedorov L, Herrenknecht K, Kemler R: Lack of beta-catenin affects mouse development at gastrulation. Development 1995, 121:3529-3537.

17. Jamin SP, Arango NA, Mishina Y, Hanks MC, Behringer RR: Requirement of Bmpr1a for Mullerian duct regression during male sexual development. Nat Genet 2002, 32:408-410.

18. Arango NA, Szotek PP, Manganaro TF, Oliva E, Donahoe PK, Teixeira J: Conditional deletion of beta-catenin in the mesenchyme of the developing mouse uterus results in a switch to adipogenesis in the myometrium. Dev Biol 2005, 288:276-283.

19. Deutscher $\mathrm{E}$, Hung-Chang Yao H: Essential roles of mesenchyme-derived beta-catenin in mouse Mullerian duct morphogenesis. Dev Biol 2007, 307:227-236.

20. Martin L, Finn CA: Duration of progesterone treatment required for a stromal response to oestradiol-17-beta in the uterus of the mouse. $J$ Endocrinol 1969, 44:279-280.

21. Jeong JW, Lee HS, Franco HL, Broaddus RR, Taketo MM, Tsai SY, Lydon JP, Demayo FJ: Beta-catenin mediates glandular formation and dysregulation of beta-catenin induces hyperplasia formation in the murine uterus. Oncogene 2009, 28:31-40.

22. Zhu L, Pollard JW: Estradiol-17beta regulates mouse uterine epithelial cell proliferation through insulin-like growth factor 1 signaling. Proc Natl Acad Sci 2007, 104:15847-15851.

23. Chen B, Pan H, Zhu L, Deng Y, Pollard JW: Progesterone inhibits the estrogen-induced phosphoinositide 3-kinase->AKT->GSK-3beta->cyclin D1->pRB pathway to block uterine epithelial cell proliferation. $\mathrm{Mol}$ Endocrinol 2005, 19:1978-1990.

24. Winuthayanon W, Hewitt SC, Orvis GD, Behringer RR, Korach KS: Uterine epithelial estrogen receptor alpha is dispensable for proliferation but essential for complete biological and biochemical responses. Proc Natl Acad Sci 2010, 107:19272-19275.

25. Martin L, Finn CA: Hormonal regulation of cell division in epithelial and connective tissues of the mouse uterus. J Endocrinol 1968, 41:363-371.

26. Franco HL, Dai D, Lee KY, Rubel CA, Roop D, Boerboom D, Jeong JW, Lyson JP, Bagchi IC, Bagchi MK, Demayo FJ: WNT4 is a key regulator of normal postnatal uterine development and progesterone signaling during embryo implanation and decidualization in the mouse. FASEB J 2011, 25:1176-1187.

27. Cloke B, Huhtinen K, Fusi L, Kajihara T, Yliheikkilä M, Ho KK, Teklenburg G, Lavery S, Jones MC, Trew G, Kim JJ, Lam EW, Cartwright JE, Poutanen M, Brosens JJ: The androgen and progesterone receptors regulate distinct gene networks and cellular functions in decidualizing endometrium. Endocrinology 2008, 149:4462-4474.

28. Simon L, Speiwak KA, Ekman GC, Kim J, Lydon JP, Bagchi MK, Bagchi IC, DeMayo FJ, Cooke PS: Stromal progesterone receptors mediate induction of Indian Hedgehog $(\mathrm{IHH})$ in uterine epithelium and its downstream targets in uterine stroma. Endocrinology 2009, 150:3871-3876.

29. Tan J, Paria BC, Dey SK, Das SK: Differential uterine expression of estrogen and progesterone receptors correlates with uterine preparation for implantation and decidualization in the mouse. Endocrinology 1999, 140:5310-5321.

30. Bazer FW, Slayden OD: Progesterone-induced gene expression in uterine epithelia; a myth perpetuated by conventional wisdom. Biol Reprod 2008, 79:1008-1009.

31. Li Q, Kannan A, DeMayo FJ, Lyson JP, Cooke PS, Yamagishi H, Srivastava D, Bagchi MK, Bagchi IC: The antiproliferative action of progesterone in uterine epithelium is mediated by Hand2. Science 2011, 331:912-916.

32. Franco HL, Jeong JW, Tsai SY, Lydon JP, DeMayo FJ: In vivo analysis of progesterone receptor action in the uterus during embryo implantation. Semin Cell Dev Biol 2008, 19:178-186.

33. Khatua A, Wang X, Ding T, Zhang Q, Reese J, DeMayo FJ, Paria BC: Indian hedgehog, but not histidine decarboxylase or amphiregulin, is a progesterone-regulated uterine gene in hamsters. Endocrinology 2006, 147:4079-4092.

34. Lee K, Jeong J, Kwak I, Yu CT, Lanske B, Soegiarto DW, Toftgard R, Tsai MJ, Tsai S, Lydon JP, DeMayo FJ: Indian hedgehog is a major mediator of progesterone signaling in the mouse uterus. Nat Genet 2006, 38:1204-1209.

35. Matsumoto H, Zhao X, Das SK, Hogan BL, Dey SK: Indian hedgehog as a progesterone-responsive factor meditating epithelial-mesenchymal interactions in the mouse uterus. Dev Biol 2002, 245:280-290.

36. Jeong JW, Lee KY, Han SJ, Aronow BJ, Lydon JP, O'Malley BW, DeMayo FJ: The p160 steroid receptor coactivator 2, SRC-2, regulates murine endometrial function and regulates progesterone-independent and -dependent gene expression. Endocrinology 2007, 148:4238-4250.

37. Cheon YP, Li Q, Xu X, DeMayo FJ, Bagchi IC, Bagchi MK: A genomic approach to identify novel progesterone receptor regulated pathways in the uterus during implantation. Mol Endocrinol 2002, 16:2853-2871. 
38. Mohamed OA, Jonnaert M, Labelle-Dumais C, Kuroda K, Clarke HJ, Dufort D: Uterine Wnt/beta-catenin signaling is required for implantation. Proc Natl Acad Sci 2005, 102:8579-8584.

39. Tanwar PS, Zhang L, Roberts DJ, Teixeira JM: Stromal deletion of the APC tumor suppressor in mice triggers development of endometrial cancer. Cancer Res 2011, 71:1-13.

doi:10.1186/1477-7827-10-75

Cite this article as: Zhang et al: Endometrial stromal beta-catenin is required for steroid-dependent mesenchymal-epithelial cross talk and decidualization. Reproductive Biology and Endocrinology 2012 10:75.

\section{Submit your next manuscript to BioMed Central and take full advantage of:}

- Convenient online submission

- Thorough peer review

- No space constraints or color figure charges

- Immediate publication on acceptance

- Inclusion in PubMed, CAS, Scopus and Google Scholar

- Research which is freely available for redistribution 